\title{
Pulse Pressure as a Risk Factor of Atrial Fibrillation in Black African Elderly Patients
}

\author{
Justin Koffi*, Iklo Coulibaly, Ambroise Gnaba, Bénédicte Boka, Florent Koffi, \\ Micesse Tanoh, Pinin, Maurice Kacou Guikahue \\ Institute of Cardiology of Abidjan, Hôpital de la Police Nationale Côte d'Ivoi, Université Felix Houphouet Boigny, \\ Abidjan, Côte d'Ivoire \\ Email: *koffidjinguin@yahoo.fr
}

Received 27 August 2015; accepted 23 October 2015; published 27 October 2015

Copyright (C) 2015 by authors and Scientific Research Publishing Inc.

This work is licensed under the Creative Commons Attribution International License (CC BY).

http://creativecommons.org/licenses/by/4.0/

(c) (i) Open Access

\begin{abstract}
Objective: The aim of this study was to show the prognostic role of High Pulse Pressure (PP) in the occurrence of atrial fibrillation in Black African elderly patients. Materials and Methods: In a comparative retrospective study related to $\mathbf{2 0 0 0}$ patients admitted to the Institute of Cardiology of Abidjan, from January 1991 to December 2010 for atrial fibrillation, we matched pulse pressure and atrial fibrillation in Black African elderly patients. Results: The mean age of patients was $65 \pm$ 10 years. Patients with high pulse pressure were 4.8 times more at risk to present atrial fibrillation than those with normal pulse pressure. The threshold of high risk pulse pressure was 65 mmHg. Conclusion: Pulse pressure is a factor of bad prognosis of atrial fibrillation in Black African elderly patients.
\end{abstract}

\section{Keywords}

Pulse Pressure, Atrial Fibrillation, Black African, Elderly Patients

\section{Introduction}

Atrial fibrillation is the most frequent chronic arrhythmia in adults [1] [2]. It is associated with a high risk of mortality and stroke [1] [2]. Its prevalence at the Institute of Cardiology of Abidjan was 5.5\% [3]. The prevalence of atrial fibrillation increases with age [4]. Several factors have been identified as related to the occurrence of this Rhythm Disorder. They are inter alia high blood pressure, valvular heart diseases [5] [6].

The exponential increase of atrial fibrillation incidence with the age matches with an aortic rigidity is related

\footnotetext{
${ }^{*}$ Corresponding author.
}

How to cite this paper: Koffi, J., Coulibaly, I., Gnaba, A., Boka, B., Koffi, F., Tanoh, M., Pinin and Guikahue, M.K. (2015) Pulse Pressure as a Risk Factor of Atrial Fibrillation in Black African Elderly Patients. World Journal of Cardiovascular Diseases, 5, 303-306. http://dx.doi.org/10.4236/wjcd.2015.510034 
to the age [7]. This rigidity of the aorta induces an increase of systolic blood pressure; hence of the pulse pressure. It is worth reminding that pulse pressure is the difference between systolic blood pressure and diastolic blood pressure. It depends mainly on three factors: the blood volume which strains the artery, blood compliance and reflexion waves [8].

This study aims at showing the prognostic role of high pulse pressure (PP) in the occurrence of atrial fibrillation in elderly black African patients.

\section{Materials and Methods}

This is a cohort study and all patients had initially a permanent atrial fibrillation. Pulse pressure that becomes the exposure factor thereby calculates the odds ratio. We conducted a comparative retrospective study on two matching populations of 1000 patients each, the whole of them admitted to the Medical Department of the Institute of Cardiology of Abidjan (ICA) Ivory Cost for atrial fibrillation from January 1990 to December 2010. The matching of the two groups relates to demographic factors (age, gender) and clinical parameters namely systolic, diastolic and pulse blood pressure readings. We identified a group of patients (Group 1) with high pulse pressure (higher than $65 \mathrm{mmHg}$ ) and another group (Group 2) with normal pulse pressure (lower than $65 \mathrm{mmHg}$ ). Data collected were processed with EPI INFO 6 version 04. The estimation of the relative risk was conducted thanks to the calculation of the Odds ratio confirmed by the Chi 2 Test at the threshold of 5\%. Figures lower than 5 were compared by means of the Fisher Test at the threshold of 5\%.

\section{Results}

The data were organized in Table 1 . The mean age of our patients was $65 \pm 10$ years. The sex-ratio was 1.5 with a male predominance. In both populations under study, the proportion of patients with their age comprised between 55 years and 65 years represents $70 \%$ of the overall number with a male predominance. Elderly patients with pulse pressure suffer more auricular fibrillation. Patients with a pulse pressure higher than $65 \mathrm{mmHg}$ are 4.8 times more at risk of occurrence of atrial fibrillation than patients with normal pulse pressure.

All patients were hypertensive and had a permanent SUBMITTED permanent fibrillation atriale, all under treatment whatever the molecule some under treatment were controlled, some not the most commonly used molecules with us were calcium channel blockers, calcium channel blockers, thiazide diuretics and related parties.

\section{Discussion}

The mean age of our patients was $65 \pm 10$ years. Coulibaly et al. found a mean age of 58.9 years in Abidjan [3], which could be matched to the findings of Gary which was 58 years [9].

According to the WHO, an aged person is any person whose age is comprised between 60 and 74 years [10]. Like in the literature, our study revealed a high rate of atrial fibrillation in elderly patients [3] [9]. Albrecht et al. revealed an incidence above $6 \%$ in patients aged more than 80 years [11]. This could be explained by the fact that with the age, there is a progressive increase of systolic blood pressure (SBP) and a decrease of diastolic blood pressure thus an increase of the pulse pressure (PP = SBP-DBP), mostly due to blood rigidity which is itself related to the age [7]. Regarding the relation between pulse pressure and atrial fibrillation, in our study, patients with pulse pressure $>65 \mathrm{mmHg}$ were 4.8 times more at risk of developing atrial fibrillation. Our results were in compliance with those of Gary et al. [9] who showed that any increase higher than $20 \mathrm{mmHg}$ of the pulse pressure is associated with a risk of occurrence of atrial fibrillation of $24 \%$. In this study, they showed that there was no link between systolic, diastolic, and mean blood pressure and the occurrence of atrial fibrillation. Only pulse pressure was a risk factor of auricular fibrillation. Those authors specified that only pulse pressure was associated with the occurrence of atrial fibrillation but not with mean blood pressure. Albrecht S. et al.

Table 1. Link between pulse pressure and atrial fibrillation.

\begin{tabular}{|c|c|c|c|}
\hline & $\begin{array}{l}\text { PATIENTS WITH } \\
\text { PP > } 65 \text { mmHG }\end{array}$ & $\begin{array}{l}\text { PATIENTS WITH } \\
\text { NORMAL PP }\end{array}$ & TOTAL \\
\hline ATRIAL FIBRILLATION & $1657(\mathbf{8 3} \%)$ & $343(\mathbf{1 7 \%})$ & 2000 \\
\hline
\end{tabular}

(Chi 2 = 610.73; ddl = 1; P = 0.0005; OR = 4.83; IC: 95\% = $1.97-7.53$. 
showed moreover that high blood pressure was the first etiology of atrial fibrillation with a proportion of $45 \%$ followed by hypersensitive diseases [11].

As a matter of fact, an increase of the pulse pressure induces ahypertrophy or a left concentric ventricular remodeling [12]-[14] and an increase of the size of the left auricle [15]-[17]. These morphological abnormalities cause a fibrosis and an electrical remodeling of the left auricle, a substratum of atrial fibrillation.

Other studies have shown that the elderly are mostly exposed to the risk of atrial fibrillation but in our study we wanted shown in addition to the age-related exposure to appreciate the role of elevated pulse pressure in these elderly patients

\section{Conclusions}

This comparative retrospective study shows that high pulse pressure is an important indicator of the occurrence of atrial fibrillation in elderly back African patients. A study associating pulse pressure readings and cardiac modifications sustained by an echocardiography will permit to better understand the mechanism of occurrence of this rhythm disorder.

In elderly, rigidity and atrial myocardial fibrosis are important when they pulse high blood pressure. So, high risk of atrial fibrillation occurs.

\section{References}

[1] Wolf, P.A., Abbott, R.D. and Kannel, W.B. (1991) Atrial Fibrillation as an Independent Risk Factor for Stroke: The Framingham Study. Stroke, 22, 983-988. http://dx.doi.org/10.1161/01.STR.22.8.983

[2] Stewart, S., Hart, C.L., Hole, D.J. and McMurray, J.J. (2002) A Population-Based Study of the Long-Term Risks Associated with Atrial Fibrillation: 20-Year Follow-Up of the Renfrew/Aisley Study. The American Journal of Medicine, 113, 359-364. http://dx.doi.org/10.1016/S0002-9343(02)01236-6

[3] Coulibaly, I., Anzouan-Kacou, J.B., Kouao, K.C., Kouadio, S.C. and Abouo-N’Dori, R. (2010) Fibrillation auriculaire: Epidémiologie à l'institut de cardiologie d'Abidjan. Médecine Tropicale, 70, 371-374.

[4] Go, A.S., Hylek, E.M., Phillips, K.A., et al. (2001) Prevalence of Diagnosed Atrial Fibrillation in Adults: National Implications for Rhythm Management and Stroke Prevention: The Anticoagulation and Risk Factors in Atrial Fibrillation (ATRIA) Study. Journal of the American Medical Association, 285, 2370-2375. http://dx.doi.org/10.1001/jama.285.18.2370

[5] Benjamin, E.J., Levy, D., Vaziri, S.M., D’Agostino, R.B., Belanger, A.J. and Wolf, P.A. (1994) Independent Risk Factors for Atrial Fibrillation in a Population-Based Cohort: The Framingham Heart Study. Journal of the American Medical Association, 271, 840-844. http://dx.doi.org/10.1001/jama.1994.03510350050036

[6] Wang, T.J., Parise, H., Levy, D., et al. (2004) Obesity and the Risk of New-Onset Atrial Fibrillation. Journal of the American Medical Association, 292, 2471-2477. http://dx.doi.org/10.1001/jama.292.20.2471

[7] Mitchell, G.F., Parise, H., Benjamin, E.J., et al. (2004) Changes in Blood Stiffness and Wave Reflection with Advancing Age in Healthy Men and Women: The Framingham Heart Study. Hypertension, 43, 1239-1245. http://dx.doi.org/10.1161/01.HYP.0000128420.01881.aa

[8] Benetos, A., Temmar, M. and Safar, M. (2001) Rigidité artérielle, pression pulsée et risque cardio-vasculaire. Médecine Maghreb, 92, 9-12.

[9] Gary, F.M., Ramachandran, S.V., Michelle, J.K., Helen, P., Thomas, J., Wang, Martin, G.L. (2007) Pulse Pressure and Risk of New-Onset Atrial Fibrillation. Journal of the American Medical Association, 297, 709-715. http://dx.doi.org/10.1001/jama.297.7.709

[10] Doumont, D., Libion, Fr. and Deccache, A. (1999) Les personnes âgées et leur santé: Besoins, représentations, comportements (2ème partie). UCL-RESO, Unitéd’Education pour la santé, 6.

[11] Albrecht, S., Peter, R. and Thomas, Z. (2006) Etiologie et traitement médicamenteux de la fibrillation/du flutter auriculaire. Forum Med Suisse, 6, 145-153.

[12] Gardin, J.M., Arnold, A., Gottdiener, J.S., et al. (1997) Left Ventricular Mass in the Elderly: The Cardiovascular Health Study. Hypertension, 29, 1095-1103. http://dx.doi.org/10.1161/01.HYP.29.5.1095

[13] Hundley, W.G., Kitzman, D.W., Morgan, T.M., et al. (2001) Cardiac Cycle-Dependent Changes in Aortic Area and Distensibility Are Reduced in Older Patients with Isolated Diastolic Heart Failure and Correlate with Exercise Intolerance. Journal of the American College of Cardiology, 38, 796-802. http://dx.doi.org/10.1016/S0735-1097(01)01447-4

[14] Leite-Moreira, A.F., Correia-Pinto, J. and Gillebert, T.C. (1999) Afterload Induced Changes in Myocardial Relaxation: 
A Mechanism for Diastolic Dysfunction. International Journal of Cardiovascular Research, 43, 344-353. http://dx.doi.org/10.1016/S0008-6363(99)00099-1

[15] Vaziri, S.M., Larson, M.G., Lauer, M.S., Benjamin, E.J. and Levy D. (1995) Influence of Blood Pressure on Left Atrial Size: The Framingham Heart Study. Hypertension, 25, 1155-1160. http://dx.doi.org/10.1161/01.HYP.25.6.1155

[16] Tsang, T.S., Gersh, B.J., Appleton, C.P., et al. (2002) Left Ventricular Diastolic Dysfunction as a Predictor of the First Diagnosed Non Valvular Atrial Fibrillation in 840 Elderly Men and Women. Journal of the American College of Cardiology, 40, 1636-1644. http://dx.doi.org/10.1016/S0735-1097(02)02373-2

[17] Vasan, R.S., Larson, M.G., Levy, D., Galderisi, M., Wolf, P.A. and Benjamin, E.J. (2003) Doppler Transmitral Flow Indexes and Risk of Atrial Fibrillation (The Framingham Heart Study). American Journal of Cardiology, 91, 10791083. http://dx.doi.org/10.1016/S0002-9149(03)00152-8 